\title{
Sujeto, ética y formación. En la senda de Bajtín
}

\author{
Subject, Ethics and Training. Following Bajtin's Footsteps
}

Sujeito, ética e formação. Na senda de Bajtin

\begin{abstract}
Alfonso Cárdenas Páez ${ }^{2}$
Resumen

Este artículo es resultado de la investigación DLE-033-99, patrocinada por UPN-CIUP. Trata de la relación entre el sujeto, la ética y la formación desde la perspectiva dialógica de Bajtín. Por un lado, plantea que el sujeto es un ser dialógico abierto e inconcluso, situado éticamente en relación con el otro y la cultura. Por otro lado, reconoce que la educación es un acto ético responsable; este acto se sitúa en el horizonte del sentido. Al final, propone varias conclusiones: a) la educación es un proceso ético que debe promover la comprensión dentro de los márgenes de la diversidad; b) debe atender a la disputa ideológica y a la heteroglosia social; c) debe contribuir a la formación de sujetos singulares y responsables.
\end{abstract}

Palabras clave

Sujeto, ética, responsabilidad, formación, educación, pedagogía

Abstract

This paper is the research result of project DLE-033-99, sponsored by UPN-CIUP. It deals with the relationship between the subject, ethics and training from Bakhtin's dialogic principle. On the one hand, it states that the subject is a dialogic, open and unfinished being, ethically located in relation to the other and culture. On the other hand, it recognizes that education is a responsible ethical act, situated in the horizon of sense. Finally, several conclusions are drawn: a) education is an ethical process that should promote comprehension within the range of diversity; $b$ ) it must meet the ideological dispute and social heteroglossia; c) it should contribute to the training of singular and responsible subjects.

\section{Keywords}

Subject, ethics, responsibility, formation, pedagogy, education

\section{Resumo}

Este artigo é o resultado da pesquisa DLE-033-99, patrocinada pela UPN-CIUP. Aborda a relação entre o sujeito, a ética e a formação desde a perspectiva dialógica de Bajtin. Por um lado, estabelece que o sujeito é um ser dialógico aberto e inconcluso, situado eticamente em relação com os outros e a cultura; por outro, reconhece que a educação é um ato ético responsável; esse ato está situado no horizonte do sentido. No final, propõe várias conclusões: a) o ensino é um processo ético que deve promover a compreensão dentro das margens da diversidade; b) deve atender a disputa ideológica e a heteroglosia social; c) deve contribuir à formação de sujeitos singulares es responsáveis.

Palavras clave

Sujeito, ética, responsabilidade, formação, educação, pedagogia

Artículo recibido el 21 de abril de 2016 y aprobado el 5 de agosto de 2016

1 Este trabajo es producto de la investigación DLE-033-99, patrocinada por UPN-CIUP, titulada Un marco semiodiscursivo y sociocognitivo para la enseñanza del lenguaje. Una versión preliminar del mismo fue compartida en el seminario Bajtín: Ética y Educación, del énfasis en Lenguaje y Educación del Doctorado Interinstitucional en Educación de la Universidad Pedagógica Nacional de Bogotá, Colombia.

2 Profesor de planta e investigador del Departamento de Lenguas de la Universidad Pedagógica Nacional. Coordinador del énfasis en Lenguaje y Educación del Doctorado Interinstitucional en Educación UPN-DIE. Correo electrónico: acardena@pedagogica.edu.co. 


\section{Introducción}

Una de las pretensiones de Bajtín, orgánica con las preocupaciones translingüísticas del diálogo, consistió en establecer una filosofía magna o primera, relacionada con la razón práctica; esta filosofía ética se basó en la responsabilidad de cada uno de los actos únicos, irrepetibles que realiza el sujeto en su vida, asumida como acontecimiento irrepetible. El marco fenomenológico en que se sustenta son las proyecciones desde lo dado a lo planteado, desde la vivencia a la acción y desde la acción al modo de vivir responsablemente, en las fronteras de un cronotopo general donde se cruzan el mundo de la vida con la cultura y se genera el conflicto ideológico entre las conciencias del yo y del otro, conectadas tanto por necesidad ética como estética (Zavala, 1996b).

En estas condiciones, la ética es un campo de la acción humana configurado arquitectónicamente por las vivencias de un ser que acontece en el espacio, el tiempo y los valores y llena su vida de contenidos, a partir del punto de arranque que le presta la extraposición. La ética es, entonces, la acción regida por una mirada extrapuesta que se configura desde el diálogo como zona de frontera entre la conciencia y la ideología donde se comprenden y controvierten los signos, se forma la conciencia (interior) y deviene la ideología (exterior). El diálogo es, por tanto, el campo de intersección pragmática donde la palabra entra en el discurso ajeno, donde el yo y el otro polemizan o entran en controversia, dentro de la diferencia no indiferente (Bajtín, 1982).

Si bien Bajtín jamás se ocupó de una teoría pedagógica, sus preocupaciones se situaron en la reflexión filosófica acerca de la razón práctica en cuanto accionar ético del hombre en el mundo de la vida y en el deseo de puntualizar una visión dialógica del lenguaje, organizadas ambas de forma arquitectónica, asuntos que no extrañan a la educación. Si bien los estudios del filósofo y lingüista ruso estuvieron enmarcados por la filosofía práctica, el interés educativo de sus planteamientos se pone en evidencia, dada su actitud crítica y la cercanía novedosa con las cosas del hombre; esta actitud y cercanía a las ciencias humanas (la pedagogía es una de ellas) precisa líneas de abordaje a su objeto desde la mirada profunda del texto y la visión translingüística del lenguaje que, con sus vínculos con la conciencia y con la ideología (Ponzio, 1998), asume una teoría plástica del signo cuya piedra angular es el diálogo.

Con base en lo planteado, esta breve investigación pretende reflexionar desde la postura de Bajtín acerca del lenguaje y acotar algunos temas concernientes a la formación del sujeto y la naturaleza ética de la educación, sobre los cuales se ha pronunciado de manera consistente la pedagogía crítica. Para ello, nos apoyaremos en varios principios que nos permitan comprender la perspectiva dialógica que, a distancia del consenso, admite elementos analógicos (Babolín, 2005; Beuchot, 1997, 2008; Dussel, 1980; Oñativia, 1978) e ideológicos que le imprimen a la pedagogía del lenguaje (Cárdenas, en prensa; Cárdenas \& Ardila, 2009) una nueva dirección en lo que respecta a la formación del sujeto.

\section{Lenguaje, acción educativa y responsabilidad}

Aunque en propiedad no se pueda decir que el acto educativo ocurre en el mundo de la vida, es necesario aceptar que el diálogo en que se inscribe sí tiene interés en ese ámbito de encuentro. En el diálogo educativo, intervienen dos sujetos cuyo horizonte de sentido se configura en torno a la discrepancia de conciencias que contrastan y se diferencian ideológicamente, conciencias que pugnan, la una por imponerse en algún sentido y la otra por asimilar aquello que requiere.

La naturaleza crítica de este diálogo productor de sentido (Bubnova, 1996) se origina en el mundo práctico donde transcurren las acciones humanas y se responde oportunamente a otras voces, puntos de vista, valores e ideologías; en este contexto, cada uno de los participantes asume funciones de sujeto y adopta posiciones dentro de la compleja red de sentido a través de la cual se vive la cultura. Este es el marco de la acción responsable, de la disposición para responder a las incitaciones y compromisos del otro, participar en el concierto de voces, conciencias e ideologías de la sociedad en donde vive cada ser 
humano. Este diálogo compromete la voz de cada participante, activa otras voces o se apropia de ellas para poner acentos particulares, luchar contra discursos hegemónicos que silencian la palabra disonante o reprimir las voces autoritarias que se imponen por sobre las demás.

En este escenario, el acto educativo se transforma en acontecimiento responsable o momento intensivo de la vida orientado hacia el sentido. Ese momento intensivo se produce cuando el aprendizaje es encuentro entre maestro y estudiante en extraposición profunda que atiendeal conjunto de posiciones discursivas que favorece el lenguaje. Habrá aprendizaje gracias al excedente de visión y de conocimiento que tanto el maestro como el alumno aprovechan cuando enseñan o aprenden. La acción del maestro consistirá, entonces, en crear escenarios para el diálogo o convalidar voces de los estudiantes cuando realizan el esfuerzo para situarse a la altura de las exigencias dialógicas y darle el estatus de responsividad necesario a sus voces. La mediación de que disponen uno y otro es el lenguaje o fenómeno de sentido que, asido a la semiosis y al discurso, se muestra "... como una viva concreción socio-ideológica, como una opinión contradictoria, (que) descansa para la conciencia individual sobre las fronteras de lo propio y de lo ajeno".

El acto educativo responsable como encuentro en extraposición profunda tiene valor al cargarse de sentido y luchar contra la pura repetición del significado. Tal efecto se produce cuando el aula de clase se convierte en un escenario dialógico donde participan profesores y estudiantes, un aula transformada en comunidad de habla donde, más que las declaraciones típicas del discurso pedagógico, se ambientan la pregunta, la discusión, la controversia, la diversidad de puntos de vista y perspectivas y, en especial, se promueven posiciones distintas entre los estudiantes que, a distancia de la palabra hegemónica y el conocimiento puro, responden al flujo ético, estético, ideológico y político de los contenidos.

Tal encuentro exige prácticas pedagógicas que propicien la acción educativa, ya no centrada en la palabra pura o reducida a la verbalización, menos a la única voz del maestro. Se requiere, entonces, acoger la diversidad semiótica de contenidos y fomentar el diálogo a través de la comprensión como encuentro dialógico con la contrapalabra, para dar lugar a una educación responsable que considere la arquitectónica del ser como sujeto que se construye en el ya-ser, sujeto que acontece y deviene en la medida en que busca posibilidades de ser de manera permanente.

A este propósito, cabe pensar en qué consiste esa responsabilidad dado que las escuelas, por su modo de ser institucional, acatan lo que grupos de decisión política imponen como el deber ser de la educación, lo que se debe enseñar o aprender, la orientación del discurso pedagógico y las prácticas pedagógicas, el comportamiento deseable de los agentes educativos. $\mathrm{Su}$ deber ser es un deber moral que linda con una especie de imperativo categórico.

En contraste con esta situación, Bajtín sugiere que el deber ser no es el deber moral fundado en algún principio o norma que preexista a la acción. El deber ser es parte de la naturaleza arquitectónica del ser como acontecer que busca sus posibilidades, en la tesitura del ya-ser que se ratifica como un "también soy" "junto a otros"; en este escenario, el deber ser consiste en actuar de manera oportuna, consecuente y responsable según lo disponen las posibilidades y la apertura del ser humano.

En esa situación, la responsabilidad nos exige no ser indiferentes, no vivir la vida de manera fortuita (Bajtín, 1997); la acción permanente e irrepetible, la imposibilidad de acudir a la coartada del ser, de eludir la responsabilidad; la consciencia de la imputabilidad de mis actos, el cuidado de no caer en la incongruencia de la razón teórica, la aceptación del compromiso con el otro; dar sentido a la vida mediante valores, no descuidar el tinte volitivo emocional de mis actos, individualizarme en mis actos, extraponerme en la vida y la cultura, participar del acontecer del ser, vivir la vida de manera histórica, poner en escena dialógica los actos de mi vida, todos son rasgos de que el compromiso del sujeto con la vida es indelegable.

Tal compromiso nos permite, por ejemplo, mirar el acontecer del sujeto como objeto de formación desde el punto de vista de su situación extraterritorial. 


\section{Sujeto, conciencia e ideología}

Una de las premisas de Bajtín consiste en reconocer la ambivalencia del lenguaje y la vida. A esta premisa no escapa el sujeto. Sujeto y agente, a la vez, se definen por el acontecimiento del ser, ser que acontece éticamente siempre en el universo del otro, en cuanto actúa frente al otro, al lado del otro, junto con el otro, en la frontera entre el mundo de la vida y la cultura. El ser es ser en cuanto acontece y acontece en la medida en que es un "ser juntos", donde yo y otro interactúan de diferentes modos. Tal interacción se da en la vida cotidiana donde me encuentro con los demás, me miro cara a cara con otros hombres, donde tengo conciencia de la totalidad que soy en el aquí y ahora y puedo tener la sensación de que conformo una totalidad irrepetible. "Yo soy yo por la mirada del otro", dice Bajtín.

En sentido contrario, el sujeto que se desprende de la postura bajtiniana solo puede ser un sujeto encarnado (McLaren, 1997), constituido arquitectónicamente en torno al cuerpo, el alma y el espíritu, puesto en la intersección de los puntos de contacto ético: yo-para-mí, yo-para-otro, otro-para-mí. De acuerdo con esto, "Los sujetos nos hacemos, y no tenemos esencias ni identidades fijas" (Zavala, 1996, p. 95). El ser es, no porque el yo tenga conciencia de sí mismo; es porque su conciencia deviene de la interiorización del encuentro con el otro, quien es el que me da la definición de mí mismo, de mi cuerpo, de mi alma, de mis valores. El otro es el que nos recibe cuando llegamos al mundo; es desde su posición sobre el yo y sobre el mundo de este, desde donde el otro nos ve, perspectiva desde donde cada uno de nosotros no puede verse, percibirse, vivenciarse pero a la cual siempre vuelve el yo.

En consecuencia, el ser es en cuanto existe un compromiso ético con el otro, en cuanto es ser responsable (capaz de responder) que actúa y actuando (sujeto actor) le da sentido a la vida, para convertirse en acontecimiento, en acontecimiento del ser. En esta medida, el ser participa de "la unidad única del proceso de ser", luego ser es un compromiso, una participación. Por tanto, el sujeto que se educa lo hace para individualizarse, para singularizarse mediante su penetración en el profundo sobrentendido de la cultura, gracias a su compromiso y participación en la misma. El sujeto, sometido a la doble alteridad del otro/Otro (el semejante y la cultura), va en camino de la individualización (Simondon, 2005; Virno, 2005); este hacerse singular es lo que le permite transformarse en individuo creativo.

Por eso, esa tentativa de no-ser transforma al sujeto en una zona fronteriza, lo que supone que no está definitivamente constituido, dado ni fijado en el tiempo y en el espacio. Es, por tanto, una construcción que se desplaza entre diversas posiciones (Cárdenas, 2008), avanza en la medida en que la mirada se orienta en dirección de la conciencia del otro y se empapa de las tensiones propias de la ideología. Al apoyarse esta en la heteroglosia social, el sujeto se desliza entre diferentes sentidos, se desplaza y avanza intentando configurarse, se acerca a otros o se distancia de ellos, dialoga y discute con otros, intenta existir, vivir y convivir, construir su existencia rodeado, condicionado por otros, en contacto dialógico con otros, en encuentro, polémica, intersección. Ese es el horizonte constitutivo de la vida social, donde el sentido fluye a través de diversos géneros discursivos que se prestan y se arrebatan entre sí la palabra para configurar el contexto de interacción social donde el ser se encuentra con otros (encuentro como cronotopo); este ser-evento que se pone siempre en situación responsiva, que está siempre en situación de no indiferencia, que se muestra propenso e interesado, que acentúa y valora cuando actúa, que no desliga su acción de la conciencia responsable, no puede hacer abstracción de su situación en el tiempo y en el espacio, desde donde está y actúa frente al otro. Como ser en acción, vive en los límites del mundo de la vida y el mundo de la cultura; vive en uno y se objetiva en el otro y allí se configura permanentemente como resultado de sus acciones.

En principio, el ser del sujeto se define como un "yo también soy", de lo cual adquiere conciencia cuando se encuentra con la primera realidad dada: el otro; ese encuentro resulta de la intersección arquitectónica de los puntos de contacto ético: yo-paramí, yo-para-otro, otro-para-mí. El ser es no desde la conciencia de sí mismo, sino desde la conciencia 
del otro; deviene del encuentro mutuo con el otro que me da la definición de mí mismo, de mi cuerpo (McLaren, 1997), de mi alma, de mis valores. El otro es el que nos recibe cuando llegamos al mundo; desde su posición sobre el yo y sobre el mundo, el otro nos ve y lo hace desde donde cada uno de nosotros no puede verse, percibirse, vivenciarse. Por eso, el ser es en cuanto existe un compromiso ético con el otro, en cuanto es ser responsable que actúa y responde al otro para darle sentido a la vida. Por tanto, el ser es acontecimiento y, en esta medida, participa de "la unidad única del proceso de ser"; el ser es compromiso, es participación.

Dado el encuentro en situación temporal y espacial definida, la responsabilidad se construye dentro de un marco intersubjetivo ambivalente, se juega entre dos seres humanos, situados en el mundo de la objetivación (cultura) y el mundo del acontecer del ser (vida). Así todo acto humano es bifronte, ambivalente, ambiguo. Se inscribe en la vida y en la cultura, se produce y se objetiva para transformarse en experiencia humana. La experiencia humana es concreción del ser y del sentido que la envuelven, de donde se desprende la necesidad de hacer permeables la vida, la cultura y la historia; la ciencia, el arte y la vida; lo cognitivo, lo ético y lo estético de esas orientaciones del sentido. De ahí que la vida sea un acto ético complejo, mirada que puede extenderse al acto educativo como complejo de formación en valores, al cual está sujeto el ser-estudiante.

Ser-estudiante es un acontecimiento finito y abierto al deber-ser que, más que un dispositivo moral que obligue, significa la apertura a la posibilidad de siempre "cometer" actos responsables, de que la vida estudiantil no pase en balde y apunte, por tanto, a penetrar en la cultura para consolidar la experiencia del horizonte del sentido. Sobre esta pretensión, puede fundarse la educación ética a manera de acontecimiento responsable de un sujeto moral que, en calidad de tal, no tiene coartada, porque le corresponde actuar en condiciones históricas definidas. Es esa la condición del hombre real que convive con otros hombres, actúa frente a ellos y en relación con ellos, tiene una gran capacidad de respuesta variable, heterogénea, irrepetible, total. El ser-estudiante puede, entonces, singularizarse transformándose en un ser histórico que vive y muere pero no ceja en hacer de su estudio un acto único y responsable.

Esto significa que, así como ocurre en la vida, en la educación "En general [...] no se puede hablar de ninguna norma moral, ética, del contenido de un determinado deber ser. El deber ser no posee un contenido determinado y específicamente teórico" (Bajtín, 1997, p. 11). "El deber ser es una peculiar categoría del proceder en cuanto acto [...] (todo, incluso el pensamiento y el sentimiento, representa un acto), es una orientación de la conciencia cuya estructura hemos de poner de manifiesto fenomenológicamente" (Bajtín, 1997, p. 12). Como lo advierte Bajtín, esta fenomenología de lo planteado tiene asiento en el sentido y, por tanto, se apoya en el valor desde donde adquiere su carácter dialógico de refracción y acentuación. La educación debe ser, entonces, una permanente búsqueda del sentido de la vida, de la cultura, de la ciencia y del arte; una búsqueda en la que el ser educable no cesa de transformarse en la medida en que asume su vida sin que esta pase en balde, sin coartada, en actitud responsiva, en procura del deber ser que siempre acontece.

Hechas estas consideraciones, en la condición histórica de imputabilidad e individualización del acto ético, la responsabilidad del sujeto que se educa no puede ser otra que la de convertirse en un ser singular, abierto, siempre en proceso e irrepetible en cada uno de sus actos. Luego, el sujeto que se educa no es una entidad, según la vulgata pedagógica. Es una relación de aquel ser que actúa frente a otros de manera única, absoluta, irrepetible, responsable, imputable. Esto se entiende a través del lema "no hay coartada en el ser", pues el ser arquitectónicamente no tiene excusa, no puede escapar a su responsabilidad. La educación como momento esencial de la vida es, como toda actividad humana, un fenómeno que obedece a la naturaleza del acto de apertura hacia sí mismo, hacia el otro y hacia el mundo; de ahí que la educación que repite y, por tanto, elude la responsabilidad y la imputabilidad es una educación alienante. 
Si la educación es una constante política de la sociedad, estrechamente relacionada con el quehacer vital de los seres humanos, cabe pensar con Bajtín que, quien se educa,

No $[\ldots]$ puede vivir, ni tampoco actuar con la conciencia de su ser concluida y con la concepción acabada del acontecer; para vivir (para educarse) hay que ser inconcluso, abierto para sí mismo; en todo caso, hay que vivir así en todos los momentos esenciales de la vida; es necesario ir valorativamente delante de sí mismo, no coincidir totalmente con lo que uno es. (1997, p. 14, citado en Bubnova, 1996, p. 19)

El acto ético responsable no solo tiene incidencia con respecto al otro y a sí mismo; es decir, no opera solo en función intersubjetiva. También cobija lo objetivo y lo hace desde el valor, desde el sentido ${ }^{3}$. Por eso, existe una conexión estrecha entre sujeto y objeto, donde cuentan la situación y la actitud, la posición y el valor, la conciencia y la ideología, según se desprende de Bajtín (1982). Por tal razón, la realidad deja de ser natural; como realidad física de los objetos que tenemos al frente no es puramente positiva, totalmente neutra; la realidad, al ser siempre conocida y valorada (Bajtín, 1986b), lo es porque

...toda palabra realmente pronunciada (o escrita con sentido), que está dormida en un diccionario, es expresión y producto de la interacción social de tres: del hablante (autor), del oyente (lector), y de aquel de quien o de que se habla (protagonista) (Bajtín, 1997, p. 122) (Énfasis en el original)

Esto nos dice que la realidad es tal por los actos humanos a través de los cuales se la tematiza, se la objetiva y se le otorga valor. Es este otorgamiento el acto primario sobre el cual se asienta el otro, pues el ser humano siempre está predispuesto, inclinado, propenso a mirar las cosas desde un único lugar, el

3 A propósito de la manera como la razón técnica -instrumental, dirán otros- excluye los valores, Bajtín $(1997$, p. 14) se pronuncia de la siguiente manera: "Al ser extraído de la unidad unificadora y entregado al arbitrio de la ley intrínseca de su desarrollo, todo lo técnico es terrible, porque de tiempo en tiempo puede irrumpir en esta unidad singular de la vida como una fuerza siniestra y demoledora". cual siendo inalienable está situado frente al otro/ Otro, en razón de lo cual aparece una carga ideológica y emocional (actitud afectiva y volitiva) que permea todo lo que toca.

Es por eso que los actos humanos responsables, según el acontecimiento del yo, se llenan de valor, son actos donde lo uno y la totalidad se encuentran, lo que los hace actos totales, únicos.

Cualquier pensamiento mío, con su contenido, representa $\mathrm{mi}$ acto individual y responsable, uno de los actos que constituyen toda mi vida irrepetible en un permanente actuar, puesto que mi vida en su totalidad puede examinarse como una especie de acto ético complejo: actúo mediante mi vida entera, cada acto o vivencia es un momento de mi vida en cuanto actuar ético. (Bajtín, 1997, p. 83)

El hombre como sujeto no es por sí mismo sino por sus actos, sus actos lo comprometen subjetivamente con el acontecimiento. Más allá de las determinaciones sociales y culturales, el ser sujeto es ser sujeto de acción, es participar del acontecimiento vivo de ser actuante.

Solo el acto en su totalidad es real y participa del acontecimiento unitario del ser, sólo este acto es vivo y [...] está en el proceso de generación, deviene, se realiza, siendo partícipe viviente del acontecimiento de ser: forma parte de la unidad única del proceso de ser[...] (Bajtín, 1997, pp. 7-8)

Por eso, el sujeto no es un ser acabado, completamente definido; es un ser de frontera, que vive y acontece arquitectónicamente en los límites del otro, de la cultura, del mundo de la vida que son sus determinantes pero, por paradoja, le abren las posibilidades. Este contexto de contraposición y divergencia dialógicas se manifiesta en la triada conexiva que los hombres contraen consigo mismos, los otros y el mundo.

Como resultado, dos mundos se oponen el uno al otro, mundos incomunicados entre sí y mutuamente impenetrables: el mundo de la cultura y el mundo de la vida. Este último es el único mundo en el que creamos, conocemos, contemplamos, hemos vivido y morimos. El primero es el mundo 
en el cual el acto de nuestra actividad se vuelve objetivo; el segundo es el mundo en el que este acto realmente transcurre y se cumple por única vez. El acto de nuestra acción, de nuestra vivencia, como Jano bifronte, mira hacia lados opuestos: hacia la unidad objetiva del área cultural y hacia la unicidad irrepetible de la vida transcurrida, sin que exista un plano único y unitario en el cual sus dos caras se determinen recíprocamente en su relación con una y única unidad. Esta unidad única puede ser tan sólo el acontecimiento único de ser que se produce[...] (Bajtín, 1997, p. 8)

Cualquier pensamiento mío, con su contenido, es mi acto ético [...] individual y responsable, es uno de los actos éticos de los cuales se compone mi vida única, concebida como un actuar ético permanente, porque la vida en su totalidad puede ser examinada como una especie de acto ético complejo: yo actúo mediante toda mi vida, y cada acto y cada vivencia aislada es un momento de mi vida en cuanto actuar ético. (Bajtín, 1997, p. 9)

No existen normas morales determinadas válidas por sí mismas, sino que existe el sujeto moral con determinada estructura (que no es, desde luego, psicológica ni física), con el cual hemos de contar: es este sujeto quien ha de saber qué cosa y cuándo resulta moralmente necesaria, o más exactamente, "qué es en general lo debido [...] (porque no existe un deber ser específicamente moral)" (Bajtín, 1997, p. 12).

De ahí que el sujeto se constituye en y por el lenguaje, dos complejos de acción y de sentido que inducen a considerar que ni el sujeto es fuerte, autónomo, libre, constituyente, ni el lenguaje es medio, instrumento, sino mediación. Por tanto, el hombre y el lenguaje (Heidegger, 1995) son dos factores de la existencia humana y de la cultura que se pertenecen, que se condicionan y se corresponden mutuamente.

Echando mano de Benveniste (1977), existe la "figuración ingenua" que nos induce a buscar un estado original para el surgimiento del lenguaje. Dicha figuración se produce porque no nos hemos dado cuenta de que el hombre no ha fabricado el lenguaje sino que este es constitutivo de su naturaleza por cuanto, más allá de la ficción, "nunca llegamos al hombre separado del lenguaje [...]
Es un hombre hablante el que encontramos en el mundo, un hombre hablando a otro, y el lenguaje enseña la definición misma del hombre". Por eso, "es en el lenguaje y por el lenguaje como el hombre se constituye como sujeto; porque el solo lenguaje funda en realidad, en su realidad, que es la del ser, el concepto de 'ego'" (Benveniste, 1971, p. 180).

Puestos en esta situación, el concepto de sujeto en Bajtín es bifronte, equívoco; es sujeto y agente a la vez, en ambos casos es responsable, es la relación entre lo dinámico y lo estático entre lo que se repite y lo nuevo. Esto está de acuerdo con el diálogo (Kristeva, 1974). Siguiendo la noción de extraposición, se puede colegir que el sujeto no es una entidad sino una configuración de posturas, de situaciones, de actitudes o puntos de vista desde los cuales da sentido al mundo. El sujeto, presa de las determinaciones del mundo, los demás y de sí mismo, responde a diversas modalidades de subjetividad que obedecen a las diferentes posiciones que ocupa en la cultura; por eso, el sujeto no es garantía de nada dada su escisión y su finitud en cuanto forma emergente e histórica del ser humano.

Entre tanto, la conducta expande el terreno de la praxis humana como vértice y territorio de intersección de las maneras de ser y de hacer que se expresan en la comunicación mediante propósitos, puntos de vista, perspectiva, modalidades y estrategias que inciden en la comprensión (Vygotsky, 1989) de las mediaciones semióticas a las que recurrimos.

El lenguaje no es un medio neutral que se convierte fácil y libremente en propiedad intencional del hablante: está poblado y superpoblado de intenciones ajenas que se configuran en la heteroglosia social. Su dominio, su subordinación a las intenciones y acentos propios, es un proceso difícil y complejo (Bajtín, 1986b).

Desde aquí, la reflexión sobre el tema del sujeto y el lenguaje toma un giro que apunta a la zona extraterritorial de la conciencia y la ideología. El sujeto, al intentar apoderarse de la palabra, se apodera de su indeterminación semántica lo que lo pone en situación de frontera pues la interacción comunicativa en lugar de estar prefijada por el código 
obedece a un acto único, irrepetible e imputable (Bajtín, 1997), donde la palabra está al servicio de intenciones ajenas, en situación de mutuo conocimiento, de cercanía, de encuentro que facilite a la gente "ponerse a hablar".

Por tanto, si el sujeto no está definitivamente constituido, ni fijado en el tiempo y en el espacio, es una construcción que emerge en la mirada y en la conciencia del otro y en función de la ideología. El sujeto es en cuanto se inscribe en la heteroglosia social, se desliza entre diferentes sentidos, se desplaza y avanza intentando configurarse, se acerca a otros o se distancia, dialoga y discute con otros, intenta existir, vivir y convivir, construir su existencia rodeado, condicionado por otros, en contacto dialógico con otros, se encuentra con el otro, entra en polémica con él, atiende al llamado del otro. La vida social depende, pues, de ese encuentro que, en términos de lenguaje, significa apelación a diversos géneros discursivos que se prestan y se arrebatan entre sí la palabra.

De acuerdo con lo anterior, se llega a la conclusión de que sin lenguaje no hay conciencia, que esta no es un presupuesto de la naturaleza humana ni algo dado a ella, algo previo a cualquier situación social. La conciencia no está dada en cada individuo, "La conciencia individual es un hecho ideológico y social" (1992, p. 35); por tanto, es extraterritorial, en el resultado del encuentro a través del lenguaje, de los signos, de las ideologías.

La conciencia individual se alimenta de signos, crece con base a ellos, refleja en sí su lógica y sus leyes, por lo cual desde la conciencia el sujeto también se nos muestra como un ser de frontera, en la medida en que como ser de lenguaje, es productor de sentido y este no puede darse al margen de la acción, en la medida en que sirve a múltiples funciones, propósitos a los cuales la conciencia presta su unidad integradora de esa diversidad heteroglósica del lenguaje que tal como lo plantea Bajtín “... no es un sistema abstracto de formas normativas, sino una opinión concreta y contradictoria sobre el mundo" (1986b, pp. 120-121).

No obstante esa supuesta unidad no puede llevarnos a incurrir en el error de desligar la conciencia de la ideología, pues según Bajtín y Voloshinov "La conciencia sólo deviene conciencia al llenarse de un contenido ideológico, es decir sígnico y, por ende, sólo en el proceso de interacción social" (1992, p. 34), que atraviesa tanto el llamado del otro como el encuentro con él. A diferencia de algunos movimientos que sitúan la ideología en la conciencia, en algo trascendental o en algo infrahumano, para Bajtín la ideología está en el material concreto y en el contexto de los signos que, ni más ni menos, son producto social del hombre y a esta evidencia no puede ser ajena la educación.

A tenor de estas consideraciones, el lenguaje es un fenómeno semiótico de orden social, cultural e histórico que ofrece múltiples opciones de producción de referencia que resultan de la extraposición en la cual acontecemos frente al Otro/otro y de donde nace la saturación de acentos de que se llena lo que hacemos en él y sabemos de él. Ni en su materialidad ni en su significación, los signos funcionan de manera libre ni estática; la plasticidad e indeterminación de los signos como cosas materiales y singulares (parte objetiva de la realidad) les da poder para reflejar y refractar (ideológica, valorativamente) el mundo como realidad conocida y valorada.

Por eso, a la dimensión ética se agrega el universo de lo axiológico, de la valoración, de lo ideológico. El signo demarca el territorio de lo ideológico, el cual se configura como una cadena que enlaza las conciencias individuales, que al interactuar se convocan en procura de la contrapalabra, del diálogo.

No cabe, entonces, otra alternativa que tomar distancia del significado y hablar de sentido. El sentido, como significación saturada, supone valoración. Por tanto, más que un decir sobre algo, es un punto de vista que proviene de la situación discursiva en que se encuentran los sujetos discursivos. No se puede hablar de sentido desde el puro punto de vista de la referencia, de la proposición, por cuanto esta siempre se modaliza. Hablar de sentido es hablar de significado y valoración; es hablar de ideología y, por supuesto, de sujeto modal, lo que significa que el lenguaje es más praxis que episteme (Virno, 2005).

Por eso, el sentido es una práctica que obedece a un incremento de la significación; cuando el sujeto habla siempre apela al despliegue de diferentes signos 
ya que no usa solo signos lingüísticos sino también símbolos, íconos, índices, señales. Este incremento de la representación es apertura intencional y referencial que exige el despliegue de la modalidad (tiempos, puntos de vista, modalidades, perspectiva) y de implicaciones ideológicas que transitan por la valoración y la multiplicación de puntos de vista. Este horizonte del lenguaje se configura alrededor del mundo, los sujetos que lo usan (los sujetos hablan de sí mismos, de sus modos de percibir).

El hombre está rodeado de signos en sus esferas cultural, social e histórica; gracias a ellos, tiene un gran poder de referencia. La referencia está rodeada de una densa atmósfera ideológica que envuelve al hombre y condiciona el surgimiento y desarrollo de su conciencia que vive y se desarrolla en contacto estrecho con la existencia y el mundo ideológico que le es propio.

En conclusión, la palabra es refractaria y extraterritorial, lo que identifica el lenguaje con una mediación donde coinciden conciencia e ideología. Por tanto, la educación no puede ser neutral en lo atinente al conocimiento y al comportamiento como factores típicos de la formación de la personalidad. Por lo mismo, el discurso pedagógico, además de los elementos típicos de la representación, comporta actitudes, puntos de vista, acentos, valores, etc., que debaten en la arena social del encuentro y el diálogo con el otro, cosa que no debe ser desatendida por los pedagogos.

Siguiendo las consideraciones anteriores, podemos hablar del sujeto que aprende. Si el aprendizaje para que sea tal debe responder a una actitud productiva que se configura en textos (Zavala, 1996), y si estos obedecen a la textualidad -ese más allá de la estructura-, es posible pensar en el papel que puede desempeñar la extraposición. De la misma manera que el maestro requiere de una "intensa extraposición" frente al objeto y los momentos que lo constituyen, debe ponerse fuera de los valores y del sentido, espacial y temporalmente hablando, para crear la imagen como el fondo sobre el cual se representa y darle orientación hacia el futuro, no como fin sino como acontecer no conclusivo (Bajtín, 1982), podríamos suponer que el alumno para aprender debe autoelimi- narse mediante la comprensión realista, cognoscitiva y saturada de acontecer vital.

Para lograr tales efectos, el alumno, al extraponerse, debe adoptar una conducta transgresiva de su conciencia individual; autoeliminarse a través de una lucha mortal, matar la conciencia absoluta para acceder a la metáfora de la muerte; matar aquello que suponga sometimiento. Ya no se trata de matar al padre sino de no-ser, según lo advierte Bajtín (1982).

¿Qué significan estas palabras? Significan que el estudiante, en calidad de sujeto, debe instaurar rupturas cognitivas, éticas y estéticas, afines de la "diferencia no indiferente", que lo comprometan a luchar contra la identidad apuntalada en las exclusiones. Así, transgredir la conciencia individual es romper con los esquemas discursivos dentro de los cuales se aloja la conciencia para que esta sea permeada por el torrente de la diversidad ideológica de los signos, por la heteroglosia social, por todos aquellos efectos analógicos (Cárdenas, 2007) que provienen de la plasticidad y elasticidad del signo. Autoeliminarse es aceptarse como sujeto y no creerse el iniciador de la vida y los valores, sino un continuador de la serie de actos vitales y de las valoraciones dentro de las cuales se inscribe la vida personal (Bajtín, 1982), como compromiso con la cultura.

\section{Hacia una educación responsable}

Puesta la educación en el horizonte de la responsabilidad, una de las primeras tareas que le corresponde afecta los contenidos, los cuales son de capital importancia en la perspectiva de Bajtín. Lo son como resultado de la crítica a la estética material y a la estética formal, así como por el interés ético que para él tiene el sentido y, por supuesto, los valores, factores que demarcan la convergencia de su mirada arquitectónica, dialógica y fronteriza.

Una primera aproximación localiza los contenidos en el amplio marco de la diversidad cultural:

... ni un solo acto cultural creador (la educación

lo es) tiene que ver con una materia totalmente indiferente ante el valor o completamente casual y desordenada $[\ldots]$ sino siempre con algo ya 
valorado y ordenado de algún modo, respecto del cual debe ocupar ahora su posición valorativa con responsabilidad. Así, el acto cognoscitivo encuentra la realidad ya elaborada en los conceptos del pensamiento precientífico, pero [...] ya valorada y ordenada por la conducta ética práctico-cotidiana, social y política, y la encuentra reafirmada religiosamente; por último, el acto cognoscitivo parte de la imagen estéticamente ordenada del objeto, es decir, de la visión de éste. (Bajtín, 1986b, p. 32)

Si la educación es un acto cultural fronterizo y, por tanto, impregnado de los valores culturales (cognoscitivos, éticos y estéticos), se llega a la conclusión de que, excepto el lenguaje, en la cultura no hay nada más que sentido y discurso y, por tanto, es un fenómeno de lenguaje en su acepción semiótica; por lo mismo, los educadores, así como los científicos y los poetas, tienen que vérselas en todo momento con la palabra (Bajtín, 1986b).

Si la plenitud de la palabra es el enunciado y este es una concreción lingüística y discursiva, es obvio que el enunciado requiere una actitud responsiva, porque en él se objetivan los valores y estos, a la par, objetivan dialógicamente los contenidos mediante los cuales comprendemos los mundos de la vida y la cultura. Puesto que el enunciado es un momento importante del discurso, en cualquiera de las esferas de la vida social, cabe señalar que aquí confluyen la situación verbal, la situación extraverbal y el complejo cultural de intercambio de sentido de la sociedad total. Diversas formas de comunicación acuden en la situación enunciativa (actos sociales, saludos, gestos, rituales, ceremonias, abrazos, miradas, etc.). Suponiendo que la carga significativa del enunciado concurre en la provocación de la respuesta, es preciso considerar su acontecer en la serie de otros enunciados a los cuales presupone, completa, responde, refuta en diferente grado dialógico (conversación, discusión, polémica, refutación).

Hecha esta consideración y recuperando lo dicho sobre la importancia humanística de los textos, la educación debe crear conciencia del uso de los géneros discursivos y de la importancia de los enunciados para propiciar diversos tipos de interacción discursiva que multipliquen las respuestas y pongan a los sujetos en condición práctica de no dejar pasar la vida en balde, de vivir la vida como compromiso con el otro, de participar en la acción social sin escudarse en coartada alguna. Es en esta situación donde se configuran los cronotopos y se manifiesta la función dialógica del lenguaje como búsqueda, llamado de y encuentro con el otro, voluntad dialógica de compartir significaciones distintas, contexto auténtico de encuentro interhumano y de ámbitos de participación y actuación donde se integran los factores típicos de la formación humana

Este es, también, el contexto del acontecimiento y, por supuesto, de la discrepancia, del conflicto diferencial entre el yo y el otro/Otro, relación dinámica que media en el encuentro intersubjetivo e interobjetivo, donde se produce la transformación de ambos que, situados en contextos heterogéneos, tienen miradas, puntos de vista y perspectivas que no concuerdan entre sí. De acuerdo con esta circunstancia, ninguno tiene jerarquía o poder sobre el otro, ninguno puede alegar prerrogativa alguna sobre el otro, ni privilegio de tomar decisiones por sí mismo.

Este ámbito del sentido no es otra cosa que sentido de la diferencia que se expresa mediante valoración, porque las cosas con las que "tengo que ver" no son ajenas al ser como acontecer puesto en situación de doble alteridad; ellas participan del acontecimiento responsable y, por tanto, están teñidas de mis acentos, de mi tono emocional y volitivo, además de la carga valorativa del ya ser puesto en la cultura.

El acontecer responsable, anejo de una nueva concepción del deber y extraño al punto de vista deontológico de la obligación que se sobrepone a todos como categoría formal, conviene en todos sus tonos (estético, educativo, científico, moral), en la perspectiva del sentido con una concepción donde el deber “... reside, en cambio, en la unidad de mi única vida responsable como se manifiesta en la unicidad de la elección responsable" (Ponzio, 1997, p. 229), en su realización histórica y social, única, indelegable, irrepetible, en relación con el otro que nos abarca, nos determina. 


\section{Conclusiones}

Las tesis expuestas en esta breve investigación apuntan hacia el cultivo arquitectónico del ser humano (cuerpo, alma y espíritu) y establecen la necesidad de concebirlo en las facetas del ya-ser en la cultura, del ser-acontecer frente al otro/Otro y del deber-ser en los valores. Por igual, al prestar atención a los valores nos sitúan en la perspectiva del sentido que implica la diversidad, la interculturalidad, así como la inexistencia de un sentido último de la educación, ante lo cual hay que mirarla en su índole ideológica.

Esta identificación en el horizonte axiológico del otro/Otro supone que sin reconocimiento de este doble no hay conciencia lingüística pero tampoco crítica dialógica. Crítica porque asume el horizonte político de la alteridad, y dialógica porque en ella conviven el conflicto, la verdad simultánea y profunda y la fuerza necesaria de los argumentos. Por tanto, una educación crítica es dialógica en la medida en que, al cortar el circuito monológico y demostrativo de la ciencia, abre el conocimiento hacia fuentes éticas y ángulos políticos del saber, plenos de valoraciones y acentos. En atención a esto, el lenguaje no pierde su poder social en el discurso de la ciencia.

El diálogo, como puente entre los principios y los sentimientos morales, permite relativizar el ideal educativo de libertad pues, más allá de su valor teórico técnico, la libertad es un posible ético cuando se desarrolla el diálogo responsable y sin coacciones, el cual, en la perspectiva de Vygotsky (1989), significa que la educación es el dominio del desarrollo social gracias a la mediación consciente de los signos, es decir, a la deliberada actividad de encuentro con el otro y la transformación del mundo mediante instrumentación semiótica.

El diálogo es, sin duda, factor importante del aprendizaje en diferentes ámbitos cosmovisionarios: cognitivo, ético y estético; por eso, a la escuela le corresponde desarrollar la "inteligencia cultural" en los aspectos cognitivo, interactivo, comunicativo, práctico y de la acción humana, de manera que el hombre pueda funcionar en diferentes ámbitos sociales y se convierta en un ser transformador tal cual lo indica Freire (1997).
Siguiendo esa dirección, uno de los objetivos que persigue la educación de hoy se concentra en los valores, para lo cual debe estar anclada, como lo dice Freire (1997, p. 35), en la "corporeidad del ejemplo", en la actitud responsiva frente al otro, en el reconocimiento y el respeto por la diferencia que, en la pretensión de darle sentido a lo que aprenden los muchachos, no puede perder de vista la naturaleza de la relación, el hacer posible la interacción, reconocer la diferencia, promover la expresión, llevar la educación a la vida y a la cultura y traerla de allá también.

Por eso, la educación no puede marginarse de la heteroglosia social, de la diversidad de puntos de vista, de la polifonía, del diálogo, la discusión y la polémica. Este ámbito de la diversidad donde hablan hombres y mujeres, jóvenes y viejos, desde su cultura, ejerciendo cada uno diversos papeles y con su estatus, en el ejercicio de profesiones y oficios, con propósitos diferentes y con puntos de vista que confrontan entre sí, no admite concluir que el nivel de representación sea siempre el mismo.

El uso social del lenguaje -cosa que ocurre en el aula como comunidad de habla- es un concierto de voces que están en diálogo, en discusión, en polémica. Es el universo divergente donde hombres y mujeres, jóvenes y viejos, cada uno en sus diversos papeles y con su estatus, en sus prácticas discursivas (reflexión, análisis, interpretación, argumentación, demostración, persuasión, comprensión, etc.) apelamos al lenguaje; donde cada cual habla desde su cultura, con propósitos diferentes y con puntos de vista que confrontan entre sí; donde el nivel de representación jamás puede ser el mismo.

La escuela no puede perder de vista que el discurso es la arena social donde se juega la diversidad cultural que, por más que queramos identificarla con un grupo o con una cultura, siempre pone en evidencia que el sentido no es un reflejo de la realidad, que la representación no apela necesariamente a la verdad sino que es una refracción de la misma y, por supuesto, está cargada de valores (Bajtín/ Voloshinov, 1992), lo que quiere decir que:

No se puede construir un enunciado sin valoración. Cada enunciado es una práctica con una 
orientación axiológica. Por eso, en la enunciación viva cualquier elemento no solo significa sino que también valora. Solamente un elemento abstracto, tomado en el sistema de la lengua y no en la estructura del enunciado, aparece como privado de valoraciones (Bajtín y Voloshinov, 1992, p. 145).

Cuando se habla de valores es preciso tener en cuenta el universo ético del otro, como diferente, en correspondencia con el hecho de que la conciencia individual es incapaz de revelar por sí misma la verdad, lo cual exige el diálogo como heteroglosia necesaria para la sobrevivencia de la humanidad (Rodríguez, 1996). El terreno de los valores no es otro que el del ser humano asumido éticamente en su diferencia no indiferente. Por eso, el lenguaje desempeña un papel fundamental como mediación ética que abre el horizonte hacia el otro mediante el diálogo en el aula, la cual ha de transformarse en una comunidad de habla. El diálogo solo puede darse entre diferentes no indiferentes.

Si la educación nos inscribe dentro de la diversidad cultural con el fin de que avancemos en el ser sujetos para convertirnos en individuos singulares $\mathrm{y}$, por tanto, creativos, la vía ética debe ajustar las relaciones entre la vida, la ciencia y el arte es la responsabilidad, pues el hombre al situarse entre esos mundos como ser en acción, vive y se objetiva en cada uno de ellos, actúa el vivir en el mundo de la vida, vive el resultado de sus acciones en otros y se extrapone profundamente en la cultura. Este tránsito supone una doble responsabilidad del aprendizaje (Bajtín, 1987): la que concierne a la experiencia vivida mediante la cual se construye el significado objetivo de una determinada esfera de la cultura ("responsabilidad especial") y la correspondiente a la eventualidad única del acto que me hace moralmente responsable de mis acciones ("responsabilidad moral") que, a pesar de la contingencia, pertenece al mundo donde efectivamente vivimos y nos situamos, donde compartimos y nos comprometemos como reto fundamental de la educación.

\section{Referencias bibliográficas}

Bajtín, M. M. (1982). Estética de la creación verbal. (T. Bubnova, trad.). México: Siglo xxi.

Bajtín, M. M. (1986a). Problemas de la poética de Dostoievski. México: Fondo de Cultura Económica.

Bajtín, M. M. (1986b). Problemas de literatura y estética. La Habana.

Bajtín, M. M. (1997). Hacia una filosofía del acto ético. De los borradores y otros escritos. Barcelona: Anthropos.

Bajtín, M. y Voloshinov, V. (1992). El marxismo y la filosofía del lenguaje. Madrid: Alianza.

Beuchot, M. (1997). Tratado de hermenéutica analógica. México: UNAM.

Beuchot, M. (2008). Abducción y analogía. En Analogía. Recuperado de http://www.unav.es/gep/AN/ Beuchot.html.

Bubnova, T. (1996). Bajtín en la encrucijada dialógica (datos y comentarios para contribuir a la confusión general). En Bajtín y sus apócrifos (pp. 13-72). Barcelona: Anthropos.

Cárdenas, A. (2007). Hacia una didáctica de lo analógico. En AA.VV. Red-Lecturas 2 (pp. 206-216). Medellín: Universidad de Antioquia-Gobernación de Antioquia.

Cárdenas, A. (2008). Lenguaje, sujeto y formación. Interacción, 8, 87-104.

Cárdenas, A. (en prensa). Elementos para una pedagogía del lenguaje. Bogotá: Universidad Pedagógica Nacional.

Cárdenas, A. y Ardila, F. (2009). Lenguaje, dialogismo y educación. Folios, 29, 37-50.

Charaudeau, P. (1983). Langage et discours-Eléments de semiolingüistique. París: Hachette.

Dussel, E. (1980). La pedagógica latinoamericana. Bogotá: Nueva América.

Freire, P. (1997). Pedagogía de la autonomía. México: Siglo XXI.

Heidegger, M. (1995). El ser y el tiempo (2. ${ }^{\text {a }}$ ed.). Bogotá: Fondo de Cultura Económica.

Kristeva, J. (1974). El texto de la novela. Barcelona: Lumen.

McLaren, P. (1997). Pedagogía crítica y cultura depredadora. Barcelona: Paidós.

Oñativia, O. (1978). Antropología de la conducta. Buenos Aires: Guadalupe. 
Ponzio, A. (1997). Para una filosofía de la acción responsable. En M. Bajtín. Hacia una filosofía del acto ético. De los borradores y otros escritos (pp. 225-245). Barcelona: Anthropos.

Ponzio, A. (1998). La revolución bajtiniana. Madrid: Cátedra.

Rodríguez, A. (1996). Bajtín y el deseo del otro: lenguaje, cultura y el espacio de la ética. En I. Zavala, Bajtín y sus apócrifos (p. 191). Barcelona: Anthropos.

Simondon (2005). L'individuation a la lumière des notions de forme et d'information. Grenoble: Jérome Millon.

Vygotsky, L. S. (1978). Pensamiento y lenguaje. Buenos Aires: Paidós.

Vygotsky, L. S. (1989). El desarrollo de los procesos psicológicos superiores. Barcelona: Editorial Crítica.

Zavala, I. (1996a). Escuchar a Bajtín. Barcelona: Montesinos.

Zavala, I. (1996b). Bajtín y sus apócrifos. Barcelona. Anthropos. 